\title{
Atrioventricular septal defects among infants in Europe: a population-based study of prevalence, associated anomalies, and survival
}

\author{
Nikolas Christensen, ${ }^{1}$ Helle Andersen, ${ }^{1}$ Ester Garne, ${ }^{2}$ Diana Wellesley, ${ }^{3}$ Marie-Claude Addor, ${ }^{4}$ \\ Martin Haeusler, ${ }^{5}$ Babak Khoshnood, ${ }^{6}$ Carmel Mullaney, ${ }^{7}$ Judith Rankin, ${ }^{8}$ David Tucker ${ }^{9}$ \\ ${ }^{1}$ Hans Christian Andersen Children's Hospital, Odense University Hospital, Odense; ${ }^{2}$ Paediatric Department, \\ Hospital Lillebaelt, Kolding, Denmark; ${ }^{3}$ Faculty of Medicine and Wessex Clinical Genetics Service, University \\ Hospital Southampton, Southampton, United Kingdom; ${ }^{4}$ Division of Medical Genetics, Centre Hospitalier \\ Universitaire Vaudois, Lausanne, Switzerland; ${ }^{5}$ Department of Obstetrics and Gynecology, Medical University of \\ Graz, Graz, Austria; ${ }^{6}$ INSERM U953, Hopital Saint Vincent de Paul, Paris, France; ${ }^{7}$ Department of Public \\ Health, HSE South (South East), Kilkenny, Ireland; ${ }^{8}$ Institute of Health and Society, Newcastle University, \\ Newcastle; ${ }^{9}$ Congenital Anomaly Register and Information Service for Wales, Wales, United Kingdom
}

\begin{abstract}
Objective: To describe the epidemiology of chromosomal and non-chromosomal cases of atrioventricular septal defects in Europe. Methods: Data were obtained from EUROCAT, a European network of population-based registries collecting data on congenital anomalies. Data from 13 registries for the period 2000-2008 were included. Results: There was a total of 993 cases of atrioventricular septal defects, with a total prevalence of 5.3 per 10,000 births (95\% confidence interval 4.1 to 6.5). Of the total cases, 250 were isolated cardiac lesions, 583 were chromosomal cases, 79 had multiple anomalies, 58 had heterotaxia sequence, and 23 had a monogenic syndrome. The total prevalence of chromosomal cases was 3.1 per 10,000 (95\% confidence interval 1.9 to 4.3), with a large variation between registers. Of the 993 cases, 639 cases were live births, 45 were stillbirths, and 309 were terminations of pregnancy owing to foetal anomaly. Among the groups, additional associated cardiac anomalies were most frequent in heterotaxia cases $(38 \%)$ and least frequent in chromosomal cases $(8 \%)$. Coarctation of the aorta was the most common associated cardiac defect. The 1-week survival rate for live births was $94 \%$. Conclusion: Of all cases, three-quarters were associated with other anomalies, both chromosomal and non-chromosomal. For infants with atrioventricular septal defects and no chromosomal anomalies, cardiac defects were often more complex compared with infants with atrioventricular septal defects and a chromosomal anomaly. Clinical outcomes for atrioventricular septal defects varied between regions. The proportion of termination of pregnancy for foetal anomaly was higher for cases with multiple anomalies, chromosomal anomalies, and heterotaxia sequence.
\end{abstract}

Keywords: Common atrioventricular canal; endocardial cushion defect; epidemiology

Received: 7 May 2012; Accepted: 19 August 2012; First published online: 27 November 2012

A TRIOVENTRICULAR SEPTAL DEFECT, ALSO KNOWN as endocardial cushion defect, common atrioventricular canal, or complete atrioventricular canal, is a serious cardiac anomaly with a central defect involving both the ventricular and atrial

Correspondence to: H. Andersen, MD, Hans Christian Andersen Children's Hospital, Odense University Hospital, Sdr Boulevard 29, DK-5000, Odense C, Denmark. Tel: +45 6541 1519; Fax: +45 6591 1862; E-mail: helle.a@ouh. regionsyddanmark.dk septum and a common atrioventricular valve across the defect. The defect may be partial or total and include the dominance of one ventricle - an unbalanced atrioventricular septal defect - and may have associated cardiac anomalies resulting in severe heart failure in early infancy. ${ }^{1}$ Surgery can be performed within the first year of life with good results, but later corrective surgery of one or both atrioventricular valves may be necessary. Studies show variations in survival ranging from $65 \%$ to $84.1 \%$ 
20 years post surgery. ${ }^{2-4}$ However, none of these studies included unbalanced atrioventricular septal defects for which survival is known to be worse.

Atrioventricular septal defect is often seen in infants with Down syndrome and other karyotype anomalies. ${ }^{6}$ However, studies report a large variation in the proportion of cases with atrioventricular septal defect and an associated karyotype anomaly. ${ }^{6,7}$ A large population-based study from California showed that $54 \%$ of infants with atrioventricular septal defect had Down syndrome, whereas a study by Huggon et al found 35.5\%.,

Few studies have reported the epidemiology of atrioventricular septal defect, and of those that do only a very few have been population based. ${ }^{6,7}$

Atrioventricular septal defect is most commonly diagnosed prenatally within the second trimester, although some cases may be diagnosed earlier. ${ }^{8,9}$ After the prenatal diagnosis of atrioventricular septal defect, health professionals may inform the parents of the risk of Down syndrome and other anomalies, and may offer prenatal karyotype testing. Accurate data on the epidemiology and survival of atrioventricular septal defect will be very useful in the counselling of parents when a prenatal diagnosis of atrioventricular septal defect is made.

The aim of this study is to describe the epidemiology of atrioventricular septal defect, particularly the prevalence of chromosomal and non-chromosomal atrioventricular septal defect.

\section{Materials and methods}

Data analysed in this study were obtained from EUROCAT, a European network of population-based registries collecting data on congenital anomalies. EUROCAT obtains information on foetuses and infants born with major congenital and chromosomal anomalies. Minor anomalies are disregarded according to the EUROCAT list of exclusions (http://www. eurocat-network.eu/aboutus/datacollection/guidelines forregistration/malformationcodingguides). Information is obtained from hospital records, post-mortem examinations, and birth and death certificates. EUROCAT covers more than 1.5 million births per year from 43 registries in 20 countries (www.eurocatnetwork.eu). ${ }^{10,11}$ For this study, all full member EUROCAT registries were invited to participate. Data from 13 registries covering 993 cases of atrioventricular septal defect (International Classification of Diseases-9 and -10 codes 7456 or Q21.2) from 2000 to 2008 were included. Not all registries covered the entire study period. Cases were classified into four different groups using a computer algorithm. ${ }^{12}$ Each case was classified according to associated non-cardiac anomalies and allocated in groups of either isolated cardiac anomaly, chromosomal anomalies, monogenic syndrome, or potentially multiple anomaly. The potentially multiple anomaly cases were manually reviewed by three of the authors - Ester Garne, Diana Wellesley, and Nikolas Christensen. Multiple congenital anomaly was defined as a minimum of two major congenital anomalies in two different organ systems. During the manual review, cases were allocated to a new subgroup: heterotaxia sequence. Heterotaxia sequence was defined as two or more of the following anomalies: asplenia/polysplenia, bilaterally bi- or trilobed lungs, situs inversus, midline liver, right-sided stomach, intestinal malrotation, dextrocardia, or atrial isomerism. ${ }^{1,13-15}$ If other organs were involved, the case was classified as multiple congenital anomaly.

All cardiac defects were reviewed manually (Helle Andersen and Nikolas Christensen), and cases not compatible with atrioventricular septal defect were excluded. The diagnosis of atrioventricular septal defect was subdivided into either isolated complete atrioventricular septal defect, isolated primum atrial septal defect, atrioventricular septal defect with associated cardiac defects, or unbalanced atrioventricular septal defect. Cases with the text partial or incomplete atrioventricular septal defect were categorised as primum atrial septal defect. Unbalanced atrioventricular septal defect includes cases with a hypoplastic ventricle or hypoplastic left/right heart syndrome.

Prevalence and epidemiological data - type of birth, birth weight, gestational age at prenatal discovery, 1-year survival, and maternal age - will be given for each group.

Descriptive analyses were performed and Chi-square test was used for statistical testing. The level of significance was set at 0.05 .

The total number of births covered in the 13 registries was $1,865,403$.

\section{Results}

During the 9-year study period, a total of 993 cases of atrioventricular septal defect were diagnosed, with a total prevalence of 5.3 per 10,000 births (95\% confidence interval 4.1 to 6.5 ). Live births accounted for 639 cases (64\%). Stillbirths were present in 45 cases (5\%). In 309 cases $(31 \%)$, there was a termination of pregnancy owing to foetal anomaly, accounting for $54 \%$ of those prenatally diagnosed.

Table 1 shows the prevalence of atrioventricular septal defect in the 13 registries. The total prevalence of atrioventricular septal defect varied from 2.1 per 10,000 births in Antwerp, Belgium, to 7.0 in Switzerland. There was a significant 
Table 1. Birth type and prevalence of the different European regions during 2000-2008.

\begin{tabular}{|c|c|c|c|c|c|c|c|c|c|c|c|c|c|c|}
\hline Registry & $\begin{array}{l}\text { Total } \\
\text { births }\end{array}$ & $\begin{array}{l}\text { Total } \\
\text { cases }\end{array}$ & $\begin{array}{l}\text { Live } \\
\text { births } \\
(\%)\end{array}$ & $\begin{array}{l}\text { Stillbirths } \\
(\%)\end{array}$ & $\begin{array}{l}\text { Termination } \\
\text { of pregnancy } \\
\text { for foetal } \\
\text { anomaly (\%) }\end{array}$ & $\begin{array}{l}\text { Total } \\
\text { prevalence* }\end{array}$ & $\begin{array}{l}\text { Total } \\
\text { chromosomal } \\
\text { cases (\%) }\end{array}$ & $\begin{array}{l}\text { Non- } \\
\text { chromosomal } \\
\text { cases }\end{array}$ & $\begin{array}{l}\text { Chromosomal } \\
\text { prevalence* }\end{array}$ & $\begin{array}{l}\text { Non- } \\
\text { chromosomal } \\
\text { prevalence* }\end{array}$ & $\begin{array}{l}\text { Percentage } \\
\text { prenatally } \\
\text { diagnosed } \\
\text { of total } \\
\text { cases }\end{array}$ & $\begin{array}{l}\text { Percentage } \\
\text { prenatally } \\
\text { diagnosed of } \\
\text { chromosomal } \\
\text { cases }\end{array}$ & $\begin{array}{l}\text { Percentage } \\
\text { prenatally } \\
\text { diagnosed of } \\
\text { non- } \\
\text { chromosomal } \\
\text { cases }\end{array}$ & $\begin{array}{l}\text { Median } \\
\text { gestational } \\
\text { age at } \\
\text { diagnosis for } \\
\text { non- } \\
\text { chromosomal } \\
\text { cases }\end{array}$ \\
\hline Switzerland & 65,459 & 46 & $22(48)$ & $1(2)$ & $23(50)$ & 7,0 & $27(59)$ & $19(41)$ & 4,1 & 2,9 & 70 & 93 & 37 & 20 \\
\hline $\begin{array}{l}\text { Northern England } \\
\text { (United Kingdom) }\end{array}$ & 280,909 & 188 & $131(70)$ & $9(5)$ & $48(26)$ & 6,7 & $103(55)$ & $85(45)$ & 3,7 & 3,0 & 59 & 61 & 55 & 20 \\
\hline Paris (France) & 251,255 & 166 & $62(37)$ & $10(6)$ & $94(57)$ & 6,6 & $109(66)$ & $57(34)$ & 4,3 & 2,3 & 87 & 87 & 86 & 22 \\
\hline $\begin{array}{l}\text { Cork and Kerry } \\
\text { (Ireland)** }\end{array}$ & 49,898 & 32 & $31(97)$ & $1(3)$ & $0(0)$ & 6,4 & $23(72)$ & $9(28)$ & 4,6 & 1,8 & 9 & 9 & 11 & 40 \\
\hline Barcelona (Spain)*** & 111,774 & 67 & $27(40)$ & $0(0)$ & $40(60)$ & 6,0 & $46(69)$ & $21(31)$ & 4,1 & 1,9 & 79 & 80 & 76 & 20 \\
\hline Malta & 35,689 & 21 & $21(100)$ & $0(0)$ & $0(0)$ & 5,9 & $15(71)$ & $6(29)$ & 4,2 & 1,7 & 5 & 7 & 0 & - \\
\hline $\begin{array}{l}\text { Wales (United } \\
\text { Kingdom) }\end{array}$ & 293,391 & 171 & $97(57)$ & $16(9)$ & $58(34)$ & 5,8 & $98(57)$ & $73(43)$ & 3,3 & 2,5 & 68 & 68 & 67 & 20 \\
\hline Odense (Denmark) & 48,301 & 26 & $24(92)$ & $0(0)$ & $2(8)$ & 5,4 & $8(31)$ & $18(69)$ & 1,7 & 3,7 & 31 & 38 & 28 & 24 \\
\hline Styria (Austria) & 93,484 & 43 & $34(79)$ & $2(5)$ & $7(16)$ & 4,6 & $22(51)$ & $21(49)$ & 2,4 & 2,2 & 49 & 55 & 43 & 21 \\
\hline $\begin{array}{l}\text { Wanda-Wessex } \\
\text { (United Kingdom) }\end{array}$ & 233,004 & 107 & $77(72)$ & $3(3)$ & $27(25)$ & 4,6 & $57(53)$ & $50(47)$ & 2,4 & 2,1 & 50 & 44 & 58 & 20 \\
\hline Northern Netherlands & 172,885 & 70 & $63(90)$ & $3(4)$ & $4(6)$ & 4,0 & $43(61)$ & $27(39)$ & 2,5 & 1,6 & 23 & 28 & 15 & 20 \\
\hline South-East Ireland & 60,727 & 20 & $20(100)$ & $0(0)$ & $0(0)$ & 3,3 & $16(80)$ & $4(20)$ & 2,6 & 0,7 & 0 & 0 & 0 & - \\
\hline Antwerp (Belgium) & 168,627 & 36 & $30(83)$ & $0(0)$ & $6(17)$ & 2,1 & $16(44)$ & $20(56)$ & 0,9 & 1,2 & 31 & 25 & 35 & 30 \\
\hline Total & $1,865,403$ & 993 & $639(64)$ & $45(5)$ & $309(31)$ & 5,3 & $583(59)$ & $410(41)$ & 3,1 & 2,2 & 57 & 59 & 54 & 20 \\
\hline
\end{tabular}

*Listed per 10,000 births

**Included the years $2000-2005$

***Included the years 2000-2007 
difference between registries in the proportions of chromosomal and non-chromosomal cases (p-value $<0.001)$. The proportion of chromosomal cases ranged from $31 \%$ in Denmark to $80 \%$ in South-East Ireland. In all regions except Antwerp in Belgium and Odense in Denmark, there were more chromosomal atrioventricular septal defect cases than non-chromosomal atrioventricular septal defect cases.

Significant differences in the distribution between live births, stillbirths, and termination of pregnancy owing to foetal anomaly were found among registries (p-value $<0.001)$. The highest proportions of live births were found in Malta, South-East Ireland, Cork and Kerry, Northern Netherlands, and Denmark $(\geq 90 \%)$. Termination of pregnancy owing to foetal anomaly ranged from $0 \%$ in South-East Ireland, Cork and Kerry, Ireland, and Malta to $57 \%$ and $60 \%$ in Paris, France, and Barcelona, Spain, respectively. The rate of termination of pregnancy owing to foetal anomaly varied between regions from $0 \%$ to $50 \%$ for chromosomal cases versus $0 \%$ to $41 \%$ for nonchromosomal cases.

More than half of all cases were diagnosed with a chromosomal anomaly (583 cases or $59 \%$ of total), of which 488 cases had trisomy 21. Other karyotype anomalies included trisomy 18, trisomy 13 , Turner syndrome, Klinefelter syndrome, various deletions, and unbalanced translocations. Isolated cardiac defects were seen in 250 cases $(25 \%)$. Multiple anomalies and heterotaxia sequence were present in $79(8 \%)$ and 58 cases $(6 \%)$, respectively. There were 23 cases (2\% of total) with a monogenic syndrome. The prevalence for these groups ranged from 0.1 to 3.1 per 10,000 live births, that is, monogenic syndrome and chromosomal cases, respectively. The distribution of all cases in individual groups is summarised in Figure 1. Figure 1 may be a helpful tool when counselling a pregnant woman with a foetus that is prenatally diagnosed with an atrioventricular septal defect.

For cases with chromosomal anomalies, $58 \%$ of cases were live births, for cases with multiple anomalies 53\% were live births, and for cases with isolated atrioventricular septal defect and no other cardiac defects $90 \%$ were live births.

Of all cases, $57 \%$ were diagnosed prenatally. A large variation was seen between groups. Of cases of isolated atrioventricular septal defect, $41 \%$ were prenatally diagnosed compared with $83 \%$ of cases with Heterotaxia and $76 \%$ of cases with multiple anomalies. For postnatally diagnosed cases, the majority were diagnosed within the first month after birth.

The distributions of the different types of atrioventricular septal defects are given in Table 2 . For cases with isolated primum atrial septal defect, most were either an isolated cardiac lesion (47\%), with no other major non-cardiac defects, or had a chromosomal anomaly (43\%). No cases with isolated primum atrial septal defect had heterotaxia.

Isolated complete atrioventricular septal defect was the most frequent cardiac setting seen in $72 \%$ of total cases. Among these, $69 \%$ of the cases had a chromosomal anomaly and $20 \%$ of the isolated complete atrioventricular septal defect had no other cardiac or non-cardiac anomalies - isolated cardiac lesion.

Of cases with associated cardiac defects, 34\% were isolated cardiac defects and 35\% had chromosomal anomalies. Heterotaxia was present in $16 \%$ and $13 \%$ had multiple anomalies.

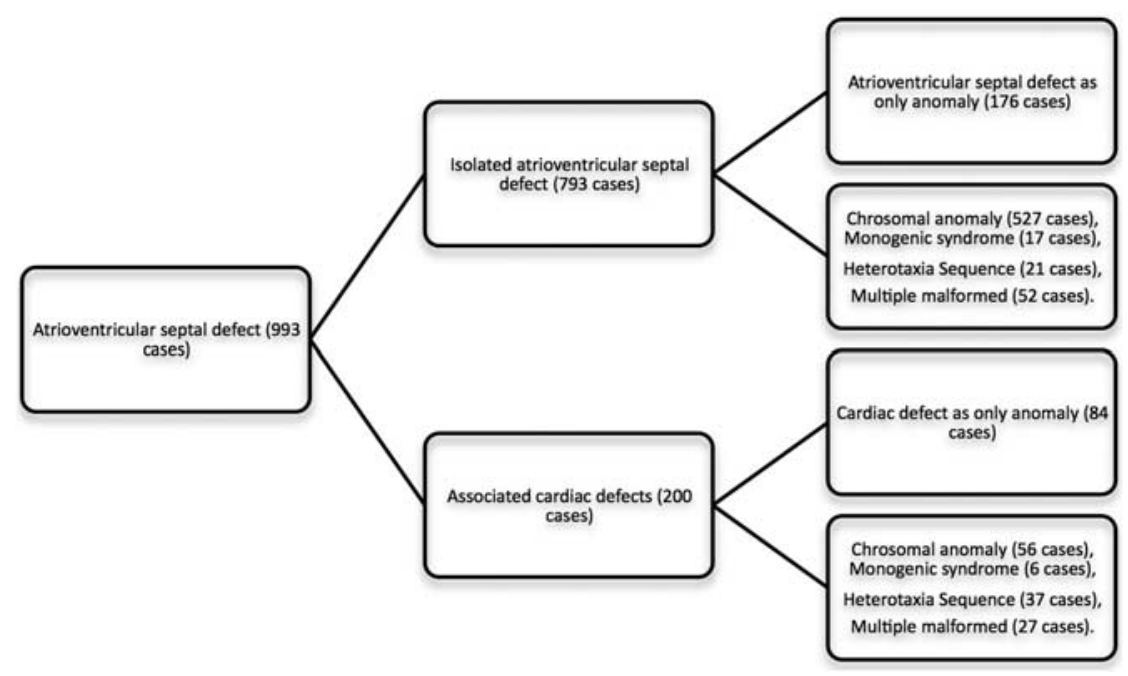

Figure 1.

Flowchart showing the distribution of cases with atrioventricular septal defect according to associated cardiac defects. For use in counselling pregnant women with a prenatally diagnosed foetus with atrioventricular septal defect. 
Table 2. Distribution of cardiac defects among groups.

\begin{tabular}{|c|c|c|c|c|c|c|}
\hline & $\begin{array}{l}\text { Isolated } \\
\text { cardiac }(\%)\end{array}$ & $\begin{array}{l}\text { Chromosomal } \\
(\%)\end{array}$ & $\begin{array}{l}\text { Monogenic } \\
\text { syndrome }(\%)\end{array}$ & $\begin{array}{l}\text { Heterotaxia } \\
(\%)\end{array}$ & $\begin{array}{l}\text { Multiple } \\
\text { anomaly (\%) }\end{array}$ & $\begin{array}{l}\text { All groups } \\
(\%)\end{array}$ \\
\hline Isolated primum atrial septal defect & $35(47)$ & $32(43)$ & $4(5)$ & $0(0)$ & $3(4)$ & $74(100)$ \\
\hline $\begin{array}{l}\text { Isolated complete atrioventricular septal } \\
\text { defect }\end{array}$ & $141(20)$ & $495(69)$ & $13(2)$ & $21(3)$ & $49(7)$ & $719(100)$ \\
\hline Associated cardiac defects & $47(34)$ & $49(35)$ & $4(3)$ & $22(16)$ & $18(13)$ & $140(100)$ \\
\hline Unbalanced atrioventricular septal defect & $27(45)$ & $7(12)$ & $2(3)$ & $15(25)$ & $9(15)$ & $60(100)$ \\
\hline Total & $250(25)$ & $583(59)$ & $23(2)$ & $58(6)$ & $79(8)$ & $993(100)$ \\
\hline
\end{tabular}

Table 3. Associated cardiac defects seen among 140 cases.

\begin{tabular}{lcc}
\hline Defect & Number & \% of total \\
\hline Coarctation of the aorta & 48 & 21 \\
Pulmonary atresia & 28 & 12 \\
Double-outlet right ventricle & 26 & 11 \\
Hypoplastic left or right ventricle & 26 & 11 \\
Transposition of the great arteries & 24 & 10 \\
Tetralogy of Fallot & 20 & 9 \\
Anomalous venous return & 17 & 7 \\
Other & 40 & 17 \\
Total & 229 & 100 \\
\hline
\end{tabular}

Table 4. Syndromes and associations among cases with atrioventricular septal defects.

\begin{tabular}{lll}
\hline Syndrome & Number & \% of all syndromes \\
\hline CHARGE & 4 & 15 \\
Noonan syndrome & 3 & 12 \\
VATER & 3 & 12 \\
Holt-Oram syndrome & 2 & 8 \\
Smith-Lemli-Opitz & 2 & 8 \\
Foetal alcohol syndrome & 2 & 8 \\
Cornelia de Lange & 1 & 4 \\
Goldenhar syndrome & 1 & 4 \\
Wardenburg & 1 & 4 \\
Other/unspecified & 7 & 27 \\
\hline
\end{tabular}

The median gestational age at prenatal diagnosis was 21 weeks for isolated primum atrial septal defect and isolated complete atrioventricular septal defect and 20 weeks for cases with associated cardiac defects and unbalanced atrioventricular septal defect.

Table 3 shows the distribution of associated cardiac defects. Coarctation of the aorta was the most frequent and was present in 48 cases, that is, $21 \%$ of the total associated cardiac defects.

Table 4 shows the 26 syndromes and associations present with atrioventricular septal defect cases. The most common were the CHARGE syndrome, Noonan syndrome, and VATER association.

Table 5 shows the anomalies seen among the 79 cases with multiple malformations. The most
Table 5. Additional congenital anomalies in cases with atrioventricular septal defects.

\begin{tabular}{lc}
\hline Affected organs & Number \\
\hline Limb & 33 \\
Urinary & 26 \\
Nervous system & 24 \\
Digestive system & 18 \\
Orofacial clefts & 13 \\
Musculoskeletal & 12 \\
Respiratory & 10 \\
Genital & 8 \\
Others & 7 \\
Abdominal wall defects & 5 \\
Eye & 2 \\
Ear, face, and neck & 1 \\
Total & 159 \\
\hline
\end{tabular}

common were limb, urinary, and nervous system anomalies accounting for $33(21 \%), 26(16 \%)$, and $24(15 \%)$ of a total of 159 anomalies, respectively.

Of all 993 cases, $599(60 \%)$ survived beyond the first week of life. For live births only, the percentage of survival at 1 week of age was $94 \%$ and survival past 1 week varied between groups from 82\% (Heterotaxia) to $96 \%$ (Isolated cardiac) for live births. For six cases, the outcome at 1 week of age was unknown.

\section{Discussion}

Our European study showed an overall prevalence of atrioventricular septal defect of 5.3 per 10,000 births ( $95 \%$ confidence interval 4.1 to 6.5 ), which is higher than in previously published literature. The reported prevalence ranges from 2 per 10,000 to 4.4 per 10,000 live births. , $8,16,17$ However, these studies included live-born cases only and only one study included the entire spectrum of atrioventricular septal defect. ${ }^{17}$ The variation in prevalence is also demonstrated by the regional differences observed in our study. There was no clear North-South or EastWest European distribution of prevalence present in our study. 
In our European population, $64 \%$ of all atrioventricular septal defect cases were live births and $31 \%$ resulted in a termination of pregnancy for foetal anomaly. In other studies, the proportions of birth types are reported with some variation. Studies on prenatally diagnosed atrioventricular septal defects mostly show a lower proportion of live births than found in this study. ${ }^{7-9,18-20}$ Delisle et $\mathrm{al}^{21}$ and Allan ${ }^{22}$ included postnatally diagnosed cases, and the proportion of live births in these studies correlates well with our findings.

The highest proportion of termination of pregnancy for foetal anomaly cases in our study was seen in cases with multiple anomalies, chromosomal anomalies, and heterotaxia. Yildırım et al did not find any significant increase in termination of pregnancy for foetal anomaly among cases with more complex cardiac lesions compared with those with isolated cardiac defects. ${ }^{19}$ Culture, prenatal screening policies, and local legislation in relation to termination of pregnancy for foetal anomaly may influence this proportion. ${ }^{23}$

Regional variation in chromosomal prevalence was seen in our study (Table 1 ). In regions with first-trimester screening for Down syndrome, the gestational age at termination of pregnancy for foetal anomaly might be too low for the diagnosis of atrioventricular septal defect either by ultrasound or by post-mortem examination. In the Danish registry, only $31 \%$ of all atrioventricular septal defect cases were reported to have a chromosomal anomaly. In this region, chorion villus sampling was the preferred invasive test offered for Down syndrome screening at a gestational age of $12-13$ weeks to women from 35 years in the period 2000-2004, and from 2005 the first trimester combined screening was offered to all women. ${ }^{24}$ With the increasing use of firsttrimester screening for Down syndrome in Europe, the overall prevalence and the chromosomal prevalence of diagnosed atrioventricular septal defect is expected to decrease.

In this study, chromosomal anomalies accounted for the majority of cases and Down syndrome was, as expected, the dominant chromosomal anomaly. ${ }^{7-9,18-21,25,26}$ Cases with isolated cardiac defects comprised a quarter of the total cases. This corresponds well with other studies. ${ }^{21,25}$ However, studies including only prenatally diagnosed cases are likely to be over-represented with more complex cases. ${ }^{7,18,22}$

The proportion of heterotaxia sequence has been reported with large variation ranging from $6 \%$ to $45 \% .^{5,8,9,14,17,20-22,25}$ In our study, we found heterotaxia in $6 \%$ of the cases. The proportion and type of monogenic syndromes in our study are similar to previously published studies. ${ }^{25,27}$
Isolated primum atrial septal defect was the cardiac lesion in 74 cases ( $7 \%$ of total cases). This figure may be underestimated in our study, as isolated primum atrial septal defect is more difficult to diagnose and therefore might not be diagnosed within the first year of life. ${ }^{14,26,28}$ Isolated primum atrial septal defect was mainly seen in patients with isolated cardiac lesions (47\%) or chromosomal anomalies (43\%), as has also been reported by Paladini et $\mathrm{al}^{26}$ No cases with isolated primum atrial septal defect had heterotaxia sequence in our study. Geva et $\mathrm{al}^{14}$ have noted that heterotaxia is more common in cases with complete atrioventricular septal defect than primum atrial septal defect.

Our study shows a strong association between isolated complete atrioventricular septal defect and chromosomal anomalies. This association is well known, especially the association with Down syndrome. ${ }^{7-9,16,18,20,21,25,29}$

Atrioventricular septal defect is often reported with associated cardiac defects. In our study, 140 cases with atrioventricular septal defect had 229 associated cardiac defects. The frequency of individual cardiac lesions has been reported with some inconsistency in the published literature. ${ }^{7,9,14,18-20,26,29,30}$ We found that coarctation of the aorta was the most prevalent, accounting for $21 \%$ of all associated cardiac defects.

For live-born infants with atrioventricular septal defect, overall survival past the first week of life was 94\% with some variation between groups. Cases with heterotaxia had the lowest survival rate, whereas cases with isolated cardiac lesions had the highest survival rate, as has been shown in other studies. $7,17,19,20,22$ Atrioventricular septal defect associated with Down syndrome has been reported to have a better survival than non-Down syndrome cases probably because of a lower proportion of severe associated cardiac defects. ${ }^{3,9}$ However, we found no significant difference in 1-week survival between chromosomal cases and non-chromosomal cases, as seen by Huggon et $\mathrm{al}^{7}$

Studies on prenatally diagnosed atrioventricular septal defects report poorer outcomes compared with studies on postnatally diagnosed cases. 7,8 Surgical studies also report a high survival rate., 3,16 Surgical studies often exclude cases not suitable for surgery or those who die before surgery can be performed. ${ }^{7}$ Therefore, caution should be used if using these studies in the counselling of parents with a foetus with a prenatal diagnosis of an atrioventricular septal defect. ${ }^{8}$

This study has a number of strengths. To our knowledge, it is the largest of its type. All cases have been thoroughly reviewed for classification of cardiac defects and syndromes, although our review was based solely on the International Classification 
of Diseases-9 and -10 codes given by the local registries. Data for the study are population based and have been routinely collected for many years using the same methodology and without bias for this specific cardiac defect.

A weakness of this study is that no cases were included if the diagnosis was made after 1 year of life. This underestimates the prevalence of primum atrial septal defect, as this defect may go unnoticed for years. This study was of a European population and may not be representative for other parts of the world or all ethnicities. ${ }^{31,32}$ Furthermore, for cases with non-isolated atrioventricular septal defect or chromosomal anomalies, it is uncertain whether the atrioventricular septal defect or another anomaly was diagnosed first.

\section{Conclusion}

The total prevalence of atrioventricular septal defect in Europe was 5.3 per 10,000 births (95\% confidence interval 4.1 to 6.5$)$. In our study, three-quarters of all atrioventricular septal defect cases were associated with chromosomal disorders or other congenital anomalies. Of the $25 \%$ with only cardiac defects, $30 \%$ had associated cardiac defects or unbalanced atrioventricular septal defect. The proportion of termination of pregnancy for foetal anomaly was high for cases with multiple anomalies, chromosomal anomalies, and heterotaxia sequence. For infants with atrioventricular septal defect and no chromosomal anomaly, cardiac defects were more often complex compared with infants with atrioventricular septal defect and a chromosomal anomaly.

\section{Acknowledgements}

Marian Bakker from The Netherlands, Miriam Gatt from Malta, Vera Nelen from Antwerp, Belgium, Mary O'Mahony from Cork, Ireland, and Joaquin Salvador from Barcelona collected data for the study. Contributorship: All co-authors have contributed significantly to this manuscript. Funding: This research received no specific funding. Competing interests: There are no competing interests.

\section{References}

1. Anderson RH, Baker EJ, Macartney FJ, Rigby ML, Shinebourne EA, Tynan M. Pediatric Cardiology. Churchill Livingstone, London, 2002, 939-981.

2. Dragulescu A, Fouilloux V, Ghez O, Fraisse A, Kreitmann B, Metras D. Complete atrioventricular canal repair under 1 year: Rastelli one-patch procedure yields excellent long-term results. Ann Thorac Surg 2008; 86: 1599-1604.

3. Boening A, Scheewe J, Heine K, et al. Long-term results after surgical correction of atrioventricular septal defects. Eur J Cardiothorac Surg 2002; 22: 167-173.
4. Tennant PW, Pearce MS, Bythell M, Rankin J. 20-year survival of children born with congenital anomalies: a population-based study. Lancet 2010; 375: 649-656.

5. Owens GE, Gomez-Fifer C, Gelehrter S, Owens ST. Outcome for patients with unbalanced atrioventricular septal defects. Pediatr Cardiol 2009; 30: 431-435.

6. Torfs CP, Christianson RE. Anomalies in Down syndrome individuals in a large population-based registry. Am J Med Genet 1998; 77: 431-438.

7. Huggon IC, Cook AC, Smeeton NC, Magee AG, Sharland GK. Atrioventricular septal defects diagnosed in fetal life: associated cardiac and extra-cardiac abnormalities and outcome. J Am Coll Cardiol 2000; 36: 593-601.

8. Rasiah SV, Ewer AK, Miller P, Wright JG, Tonks A, Kilby MD. Outcome following prenatal diagnosis of complete atrioventricular septal defect. Prenat Diagn 2008; 28: 95-101.

9. Berg C, Kaiser C, Bender F, et al. Atrioventricular septal defect in the fetus - associated conditions and outcome in 246 cases. Ultraschall Med 2009; 30: 25-32.

10. Greenlees R, Neville A, Addor M-C, et al. EUROCAT member registries: organization and activities. Birth Defects Res A Clin Mol Teratol 2011; 91 (Suppl 1): S51-S100.

11. Boyd PA, Haeusler M, Barisic I, Loane M, Garne E, Dolk H. Paper 1:The EUROCAT Network - organisation and processes. Birth Defects Res A Clin Mol Teratol 2011; 91 (Suppl 1): S2-S15.

12. Garne E, Dolk H, Loane M, et al. Paper 5: Surveillance of multiple congenital anomalies: implementation of a computer algorithm in European registers for classification of cases. Birth Defects Res A Clin Mol Teratol 2011; 91 (Suppl 1): S44-S50.

13. Peeters H, Devriendt K. Human laterality disorders. Eur J Med Genet 2006; 49: 349-362.

14. Geva T, Ayres NA, Pignatelli RH, Gajarski RJ. Echocardiographic evaluation of common atrioventricular canal defects: a study of 206 consecutive patients. Echocardiography 1996; 13: 387-400.

15. Maclean K, Dunwoodie SL. Breaking symmetry: a clinical overview of left-right patterning. Clin Genet 2004; 65: 441-457.

16. Calabrò R, Limongelli G. Complete atrioventricular canal. Orphanet J Rare Dis 2006; 1: 8.

17. Miller A, Siffel C, Lu C, Riehle-Colarusso T, Frías JL, Correa A. Long-term survival of infants with atrioventricular septal defects. J Pediatr 2010; 156: 994-1000.

18. Machado MV, Crawford DC, Anderson RH, Allan LD. Atrioventricular septal defect in prenatal life. Br Heart J 1988; 59: 352-355.

19. Yıldırım G, Gungorduk K, Yazıcıoğlu F, et al. Prenatal diagnosis of complete atrioventricular septal defect: perinatal and neonatal outcomes. Obstet Gynecol Int 2009; 2009: 958496.

20. Fesslova V, Villa L, Nava S, Boschetto C, Redaelli C, Mannarino S. Spectrum and outcome of atrioventricular septal defect in fetal life. Cardiol Young 2002; 12: 18-26.

21. Delisle MF, Sandor GG, Tessier F, Farquharson DF. Outcome of fetuses diagnosed with atrioventricular septal defect. Obstet Gynecol 1999; 94: 763-767.

22. Allan LD. Atrioventricular septal defect in the fetus. Am J Obstet Gynecol 1999; 181: 1250-1253.

23. Boyd PA, DeVigan C, Khoshnood B, Loane M, Garne E, Dolk H, and The EUROCAT Working Group. Survey of prenatal screening policies in Europe for structural malformations and chromosome anomalies, and their impact on detection and termination rates for neural tube defects and Down's syndrome. BJOG 2008; 115: 689-696.

24. Frøslev-Friis C, Hjort-Pedersen K, Henriques CU, Krogh LN, Garne E. Improved prenatal detection of chromosomal anomalies. Dan Med Bull 2011; 58: A4293.

25. Carmi R, Boughman JA, Ferencz C. Endocardial cushion defect: further studies of "isolated" versus "syndromic" occurrence. Am J Med Genet 1992; 43: 569-575. 
26. Paladini D, Volpe P, Sglavo G, et al. Partial atrioventricular septal defect in the fetus: diagnostic features and associations in a multicenter series of 30 cases. Ultrasound Obstet Gynecol 2009; 34: 268-273.

27. Digilio MC, Marino B, Toscano A, Giannotti A, Dallapiccola B. Atrioventricular canal defect without Down syndrome: a heterogeneous malformation. Am J Med Genet 1999; 85: 140-146.

28. Bini R. Partial atrioventricular canal. Orphanet encyclopedia, March 2003.

29. Marino B, Vairo U, Corno A, et al. Atrioventricular canal in Down syndrome. Prevalence of associated cardiac malformations compared with patients without Down syndrome. Am J Dis Child 1990; 144: 1120-1122.

30. ter Heide H, Thomson JD, Wharton GA, Gibbs JL. Poor sensitivity of routine fetal anomaly ultrasound screening for antenatal detection of atrioventricular septal defect. Heart 2004; 90: 916-917.

31. Hartman RJ, Riehle-Colarusso T, Lin A, et al. Descriptive study of nonsyndromic atrioventricular septal defects in the National Birth Defects Prevention Study, 1997-2005. Am J Med Genet A 2011; 155A: 555-564.

32. Ashok M, Thangavel G, Indrani S, Suresh S. Atrioventricular septal defect - associated anomalies and aneuploidy in prenatal life. Indian Pediatr 2003; 40: 659-664. 